\title{
"Você faz o que te faz feliz?" Então, "abra a felicidade": as semelhanças entre as narrativas publicitárias e os relatos sobre trajetórias profissionais
}

\author{
"Do you do what makes you happy?" So, "open happiness": the \\ similarities among narratives of advertisements on television and of \\ people that changed their career
}

\author{
"Usted hace lo que le hace feliz?" Entonces, "abra la felicidad": \\ las similitudes entre las narrativas de la publicidad e los relatos de \\ trayectorias profesionales
}

Tatiana Oliveira Siciliano | tatios@terra.com.br

Pontifícia Universidade Católica, Departamento de Comunicação, Programa de Pós-Graduação em Comunicação Social. Rio de Janeiro, Brasil.

\section{Resumo}

Este artigo propõe uma reflexão sobre como a categoria felicidade e a ideia de bem-estar estão entranhadas na lógica do consumidor moderno, a partir da comparação de 20 depoimentos sobre trajetórias profissionais de pessoas provenientes das camadas médias urbanas que mudaram de profissão, narrativas publicitárias e happy ending de telenovelas. Minha hipótese é de que existem semelhanças entre as narrativas dos que mudaram intencionalmente de profissão e a lógica do consumidor, pois o consumo pode ser visto como um configurador de identidades. As metamorfoses nas profissões aspiram a experiências mais autênticas e à conquista da felicidade e do bem-estar. Assim, além de prover o sustento, o trabalho deve 'expressar os próprios trabalhadores'.

Palavras-chave: Trajetórias profissionais; narrativas individuais sobre felicidade; propaganda em televisão; subjetividade; consumo.

\begin{abstract}
This article proposes a reflection on the happiness category and the welfare of people expressing how they are embedded in the logic of the modern consumer, based on the comparison of 20 narratives of people from middle class who have changed their careers and narratives of advertisements on television and happy ending of soap operas. My hypothesis is that there are similarities between the stories of who have changed intentionally its career and the consumer logic because consumption might be seen as an expression of the consumer identity. The metamorphosis in careers aims more authentic experiences and the conquest of happiness and welfare. Thus, in addition to providing sustenance, the work must 'express the workers themselves'.
\end{abstract}

Keywords: Professional trajectories; narratives about happiness; advertisements on television; subjectivity; consumer. 


\section{Resumen}

Este artículo propone una reflexión sobre como la categoría felicidad y la idea de bienestar están entrañadas en la lógica del consumidor moderno, a partir de la comparación de 20 declaraciones sobre las trayectorias profesionales de personas de clase media que habían cambiado de profesión, narrativas de publicidades y happy ending de telenovelas. Mi hipótesis es que hay similitudes entre las historias de aquellos que intencionalmente habían cambiado de trabajo y la lógica del consumidor, porque el consumo puede ser visto como una expresión de lo consumidor y cómo modelador de identidades. Las metamorfosis en las trayectorias profesionales buscan experimentar lo más auténtico y conquistar la felicidad y el bienestar. Por lo tanto, además de proveer medios de subsistencia, el trabajo debe 'expresar los que trabajan'.

Palabras clave: Trayectoria profesional; narrativas sobre la felicidad; publicidad en televisión; subjetividad; consumo.

Declaração de conflito de interesses: A autora declara que não há quaisquer conflitos de interesse.

Fontes de financiamentos: Não houve financiamento.

Agradecimento/Contribuições adicionais: A autora é grata aos participantes do referido GT.

Histórico do artigo: Submetido: 12.out.2016 | Aceito: 25.abr.2016 | Publicado: 30.jun.2016.

Apresentação anterior: GT "Comunicação e Consumo: cultura empreendedora e espaço biográfico" do 4 Encontro de GTs do Congresso Internacional de Comunicação e Consumo (Comunicon), realizado nos dias 08, 09 e 10 de outubro de 2014 no PPGCOM da ESPM-SP. Link: http://www.espm.br/download/Anais_Comunicon_2014/gts/gtum/GT01_TATIANA_Siciliano.pdf

Licença CC BY-NC atribuição não comercial. Com essa licença é permitido acessar, baixar (download), copiar, imprimir, compartilhar, reutilizar e distribuir os artigos, desde que para uso não comercial e com a citação da fonte, conferindo os devidos créditos de autoria e menção à Reciis. Nesses casos, nenhuma permissão é necessária por parte dos autores ou dos editores. 


\section{Introdução: "Você feliz o que é que faz?"}

"Viver e não ter a vergonha de ser feliz. Cantar, e cantar e cantar. A beleza de ser um eterno aprendiz [...]" (Gonzaguinha, 1982)i.

Este artigo propõe uma reflexão sobre como as categorias felicidade e bem-estar encontram-se imbricadas à lógica do consumo moderno. Minha inquietação começou quando, após o término de um trabalho acadêmico, uma dissertação de mestrado defendida há 10 anos sobre transformações na profissão, comecei a perceber que as narrativas que embasavam tais mudanças eram muito semelhantes às propagandas de televisão que tentavam associar sua marca a estilos de vida que valorizam o bem-estar. Estilos de vida estes que também eram valorizados na música, nas telenovelas, nas séries, em vários outros produtos da indústria cultural. Daí, com distanciamento de quase uma década, passeios por outros objetos e aprofundamento acadêmico em outras áreas de interesse, percebi que as 20 entrevistas de história de vida que contavam os desejos e as angústias das mudanças intencionais de profissão de pessoas provenientes das camadas médias urbanas valorizavam a busca da felicidade, de modo muito semelhante aos discursos midiáticos. Por isso, resolvi comparar esses depoimentos mais antigos com comerciais das empresas Pão de Açúcar, Coca-Cola e Itaú Personnalité, e com o final da telenovela 'Em Família', mais recentes. Minha hipótese é de que existem semelhanças entre as narrativas dos que mudaram intencionalmente de profissão com a lógica do consumidor, pois o consumo pode ser visto como um configurador de identidades. As metamorfoses nas profissões aspiram a experiências mais autênticas, visando o encontro com a felicidade. Assim como falou Gonzaguinha, somos aprendizes buscando felicidade na vida - e a felicidade pode ser configurada por nossas expressões através do que consumimos.

As entrevistas foram realizadas para outro trabalho ${ }^{1}$, que teve como amostra 20 entrevistas - pessoais e gravadas - entre 2004 e 2005, com homens e mulheres, entre 28 e 52 anos, moradores da cidade do Rio de Janeiro, pertencentes às camadas médias urbanas, oriundos de profissões reconhecidas que exerceram por algum tempo (no mínimo cinco anos) uma determinada atividade e que voluntariamente ${ }^{\mathrm{ii}}$ mudaram (ou estavam em processo de mudança) sua referência profissional. Ou seja, pertenciam a uma categoria de classe compreendida por um ethos, caracterizado por um tipo de vida que possibilita o acesso ao sistema de informação e de educação formal, permitindo maior margem de manobra para escolhas individuais. Apesar de nem todos contarem com a mesma renda, há semelhanças nos seus 'estilos de vida' por compartirem a visão estratégica, proposta por Bourdieu², entendida como "senso prático" no jogo social, no qual o bom jogador a cada momento cumpre a exigência do jogo para alcançar seus fins, adaptando-se conforme as situações apresentadas. Mais uma vez reitero que o enfoque do presente artigo é distinto do trabalho que o originou, o qual privilegiou a tensão entre mudar e permanecer. No entanto, a concepção de que era preciso mudar para ser feliz esteve presente no discurso de todos os entrevistados. Daí a opção por uma releitura do material, mesmo que as entrevistas sejam antigas, a partir de um novo recorte: a busca da felicidade e sua consonância com os discursos do consumo moderno-contemporâneo. Uma pesquisa empírica abriu espaço para um ensaio, pois a 'lógica do consumidor' está, na contemporaneidade, espalhando-se para outras esferas de atividade como o trabalho e o lazer.

O que há em comum em uma cena romântica no capítulo final de uma telenovela, jingles que anunciam marcas de supermercado e depoimentos de pessoas que estão fazendo ou já fizeram deslocamentos em sua trajetória profissional? No caso, todas essas narrativas, sejam versões de acontecimentos reais ou

i Gonzaguinha. O que é, o que é. In: Caminhos do coração. Rio de Janeiro: EMI; 1982.

ii Apenas uma entrevistada relatou ter percebido que queria mudar de profissão, após uma situação de desemprego. No entanto, considerei o seu relato por ela ter recebido outra proposta de emprego logo após o ocorrido, mas não ter aceitado, por desejar novas experiências. 
imaginários, contam, por meio de palavras e/ou imagens, histórias de pessoas, ou personagens, que buscam o polissêmico conceito de felicidade. Mas, afinal, o que significa felicidade? O verbete do dicionário Aurélio define felicidade como "uma qualidade ou estado feliz", e o adjetivo "feliz" é atribuído a um sujeito "venturoso", "intimamente contente" e que "goza de boa sorte"3. Evocada cotidianamente na sociedade moderno-contemporânea para justificar nossos estados de espírito, a felicidade, conforme argumenta Edgar Morin $^{4}$, é um mito, uma projeção imaginária, "mas ao mesmo tempo ideia-força, busca vivida por milhões de adeptos". Aspectos que, para o autor, estão dissociados, pois, se por um lado a felicidade é objeto da ação projetiva dos sujeitos que vivem uma existência morna, por outro, serve como práxis identificadora do indivíduo a um "ideal imaginário de vida que arrisca tudo" e que é especialmente disseminado através da cultura de massa. Mas, seja alvo de projeção ou de identificação, o conceito de felicidade é "consumido"4 como uma mercadoria.

Propagandas, assim como produtos da ficção seriada são "textos sociais" $\mathrm{e}$ acionam "equivalentes funcionais do mito" 5 . Alguns comerciais são bons exemplos desse apelo. Em 2013, o supermercado Pão de Açúcar veiculou um comercial apoiado em uma trilhaiii que trazia a seguinte letra: "O que faz você feliz? Você feliz o que que faz? Você faz o que te faz feliz? O que te faz feliz você que faz! [...]. Quem quer felicidade, corre atrás. E, às vezes, ela está debaixo do nariz.”. Na propaganda feita para audiovisual, enquanto Clarice Falcão canta o jingle, aparecem panoramas urbanos, jovens dançando, correndo, andando de skate, casais namorando em diversos lugares, cenas de almoço em família, mãe com filhos que cantam juntos no carro, crianças que sorriem, cantarolam e dançam. Em 2014, o grupo do supermercado lança uma variação desta campanha, "atitude \#paraserfeliz", incitando as pessoas a fazerem algo para serem felizes, com o seguinte discurso: "sabe aqueles momentos que nos inspiram, que nos tornam protagonistas de nossa vida e felicidade? Aqui temos alguns exemplos para você se inspirar [...] Compartilhe e mostre que a felicidade é contagiante" ${ }^{\text {iv }}$. A mensagem da propaganda induz o espectador a assumir o protagonismo de sua vida, tomando atitudes que o faça feliz.

Caminho criativo semelhante tinha sido anteriormente adotado pela multinacional Coca-Cola, com "Abra a felicidade", de 2009, trilha gravada por Di Ferrero (NX Zero), Pitty e MV Bill na qual apregoavam, em coro no refrão, para "[abrir] a felicidade que tem aí". "Sentir algo novo", "curtir [com os cantores] o dia que já vem", "abrir um sorriso no rosto de alguém". Comandos que sugerem que o consumidor possa 'abrir' a felicidade ao tomar o conteúdo do refrigerantev.

Afinal, os meios de comunicação - e mais evidentemente o discurso publicitário - transformam a cultura material em "simbologias particulares através das quais nos localizamos, referenciamos e transitamos socialmente" e os publicitários - como sublinha Everardo Rocha - são bricoleurs que se apropriam de "diversos saberes", fazendo uso de signos coletivamente compartilhados como elementos constitutivos de sua narrativa. No entanto, na publicidade, o mecanismo é declarado: o intuito é atrair a atenção do consumidor, despertar seu interesse, provocar seu desejo, para finalmente, induzi-lo à ação, ou seja, à compra. Não quer dizer que o argumento publicitário seja apenas embasado na retórica racional; nem apele somente para as funções emotivas. Como bem observou Carrascoza ${ }^{8}$, a eficácia da narrativa publicitária reside na conjunção das linhas de persuasão racional e emocional. O uso da sensibilidade no processo de criação

iii Clarice Falcão canta em campanha do Pão de Açúcar. Exame [on line], 2013 maio 15 [citado em 27 jul 2014]. Disponível em: http://exame.abril.com.br/marketing/noticias/clarice-falcao-canta-em-campanha-do-pao-de-acucar?page=2

Ser feliz é só começar. Galli D, Trielli F, produtores. Carvalho RG, diretor. São Paulo: Panela Produtora; Rio de Janeiro: Conspirações Filmes; 2013 [citado em 10 ago 2015]. Campanha institucional supermercados Pão de Açúcar. Disponível em: www.youtube.com/ watch?v=Itd6hxdDZ4Y

iv Campanha atitude \#paraserfeliz, na qual o internauta poderia escrever hashtags nas fotos da campanha e postar fotos mostrando o que faz para ser feliz. [citado em 10 out 2014]. Disponível em: www.paodeacucar.com.br/praserfeliz/sobre.php 
publicitária é fundamental, pois muitas vezes esse apelo emocional mais sutil convence o consumidor, de forma inconsciente, encobrindo o propósito comercial. Deste modo, imagens com pessoas bonitas e sorridentes, recheadas por slogans e jingles cheios de promessas de felicidade não deixam de constituírem-se em modelos eficazes nesse processo de persuasão.

De forma semelhante, a associação entre o último capítulo da telenovela e o encontro da felicidade não é nova nem surpreendente. Após o percurso dos 'mocinhos' que sofrem com as peripécias dos vilões e os infortúnios da vida, é comum nas estruturas narrativas folhetinescas que os protagonistas 'bons' sejam agraciados com cenas de final feliz. 'Valeu viver', como sugere a música de Gonzaguinha, porque se lutou pela felicidade. Porém, uma telenovela que discuta a própria noção de felicidade é boa para se pensar. A obra em questão é 'Em Família', de autoria de Manoel Carlos, exibida às 21 horas na TV Globo, entre fevereiro e julho de 2014. O diálogo ocorre no último capítulo, quando um dos casais do núcleo principal, Helena e Virgílio, filosofam sobre como, apesar de todo o sofrimento pelo que passaram e das adversidades enfrentadas, conseguiram encontrar a felicidade conjugal e em família:

“- Virgílio: [...] Passamos [...] por tantas dificuldades [...] e estamos aqui juntos. Não inteiros, porque a cada dia nós vamos deixando um pedacinho [...] Mas [pausa para suspirar] felizes [sorri] [...].

- Helena - [...] eu li uma coisa uma vez, [...] que dizia que o verdadeiro caminho da felicidade é como uma corda estendida no chão, que não está ali para mostrar o caminho da felicidade, mas para fazer a gente tropeçar e cair e aprender com os próprios erros. [...] A felicidade é um aprendizado.

- Virgílio: Eu acho que a verdadeira vocação do ser humano é ser feliz. A infelicidade é um acidente evitável"vi (grifo nosso).

A telenovela 'Em Família' abordou ao longo de seus capítulos a busca da felicidade como um tema recorrente. Esse era o motivo alegado para Helena e Virgílio não apoiarem o casamento de sua filha, Luisa, e de Luisa resolver contrariar seus pais. A moça acreditava que, a despeito da oposição familiar, só seria feliz se ela se casasse com determinado rapaz. Na cena descrita acima, os pais e a filha estão em Paris, cidade dos sonhos dos três, também escolhida como cenário para o recomeço da vida em família. Já que Laerte, o noivo, motivo da discórdia entre eles morre no dia do casamento, mãe, pai e filha vão juntos para a Cidade Luz reencontrar, como família e como casal, a tão desejada felicidade. O drama da telenovela residia no fato de Luisa ter se apaixonado e quase se casado com Laerte, o primeiro amor de sua mãe. Amor que não casou-se com Helena porque tentou matar por ciúme Virgílio (na época o melhor amigo da moça), e depois pai de Luisa, no dia do seu casamento. Laerte não se casou com Helena, que, por sua vez, se casa com Virgilio. Após ser julgado no Brasil por tentativa de homicídio, cumprir uma pena curta e viver anos na Europa como músico, Laerte volta ao Brasil e se apaixona pela filha de seu primeiro amor. Muito sofrimento e fantasmas do passado vêm à tona. A relação entre mãe e filha se esgarça. A relação entre Helena e Virgilio quase termina. Após a aceitação, Laerte é punido por sua leviandade de sedutor com a morte. É assassinado por uma de suas conquistas. O fantasma do passado retorna ao mundo dos mortos, e abre espaço para a busca da felicidade. Desse modo, a infelicidade foi vista como um 'acidente inevitável' para que a felicidade pudesse ser valorizada. Além do diálogo, a cena oferecia panorâmicas de Paris, com a torre Eiffel ao fundo, e o casal aparecia sentado em um jardim, com um lago, rodeado por flores coloridas, que se assemelhava às telas dos pintores impressionistas. Assim, a felicidade, que já está contida no happy ending das novelas, não poderia ficar de fora da faixa de maior audiência pela importância que a categoria

vi Em Família. Manoel Carlos, diretor. Rio de Janeiro: Globo Comunicação e Participação S.A., 2014 [citado em 27 jul 2014]. Diálogo do último capítulo da novela exibido em 18 jul 2014. Disponível em: http://gshow.globo.com/novelas/em-familia/ capitulo/2014/7/18/nao-perca-o-ultimo-capitulo-de-em-familia.html 
assume no imaginário social, conceito aqui entendido como determinado padrão de construção mental de um grupo, certa atmosfera simbólica que paira como uma "aura", uma matriz com repertórios9.

Se existe uma associação imediata entre felicidade e telenovela e felicidade e propaganda, se faz necessário definir mais precisamente os dois tipos de narrativas. A telenovela, um dos subprodutos da narrativa seriada $^{10}$, se distingue da propaganda por contar histórias que visam ao entretenimento, estruturadas em capítulos veiculados em dias diferentes, e divididos em blocos por intervalos comerciais ${ }^{11}$. A preocupação não é persuadir, ou vender uma ideia: é contar uma história, envolver o espectador na trama. No entanto, apesar da preocupação com a qualidade dos programas, o foco na audiência, continuamente mensurado através de pesquisas, se dá, principalmente, pelo poder que determinado produto televisivo possui de atrair anunciantes para os breaks, captar ações de product placement, onde produtos e/ou serviços, são sutilmente divulgados no roteiro da própria trama ${ }^{12}$ a fim de aumentar o faturamento da emissora. Então, se narrativamente propaganda e telenovela são distintas, na prática mercadológica muitas vezes se encontram imbricadas. E as propagandas se valem, para se destacarem das demais, de recursos como o storytelling, tão caros às narrativas ficcionais seriadas. E para se pagarem como produto, as telenovelas e séries incluem ações de product placement, inserindo os produtos e serviços como personagens na trama.

Estranhamento maior se faz ao associarmos as narrativas que falam de mudanças de profissão. Tais depoimentos além de, consequentemente, incorporarem os projetos individuais e suas transformações, estando eles sempre em processo de reelaboração ${ }^{13}$, dão a impressão de serem mais subjetivos. Como compará-los à propaganda, cujo intento é persuadir para vender um produto, uma ideia ou um serviço? O elo é compreendido quando se observa como a categoria 'felicidade' apoia os discursos da construção de si e modela as sensações experimentadas nos deslocamentos profissionais, incorporando, nesse processo, a lógica do consumidor moderno. Meu argumento é de que existem muitas semelhanças entre as narrativas dos que mudaram intencionalmente de profissão com as "bases metafísicas do consumidor moderno"14. Uma das entrevistadas resume tal lógica:

"Nós nascemos para sermos felizes [...] Então, o trabalho tem que fazer você feliz, a relação afetiva tem que fazer você feliz; se não estiver fazendo vocêfeliz, você tem que estar buscando isso. E por isso eu acho que não é uma busca da profissão, é uma busca do bem-estar"vii.

Esse é o pensamento que, de forma menos direta, encontramos nos depoimentos dos demais informantes: a compreensão de que a atividade profissional não deve ser encarada apenas como sustento, mas precisa ser propulsora de felicidade, expressando seus 'eus'. A ideia de que a felicidade é uma construção pessoal, fruto de um aprendizado, do autoconhecimento, mas que, ao mesmo tempo, o indivíduo tem obrigação de 'correr atrás' (pois a verdadeira vocação do ser humano é ser feliz), perpassa todos os discursos: ficcionais, reais ou persuasivos. Desta maneira, amores, amizades e profissões, assim como os mais diversos serviços e produtos, servem como pontes para que os sujeitos alcancem a tão propalada felicidade.

Mas se os depoimentos das pessoas que mudaram de profissão e os diálogos exibidos em narrativas ficcionais televisivas, como a telenovela, oferecem modelos de projeção e de identificação para que outros se reconheçam nessas histórias de mudança, reais ou ficcionais, a publicidade seduz com imagens e promessas e convida o espectador a olhar as qualidades dos produtos e serviços anunciados. Ao fazer a mediação entre as esferas da produção e do consumo, a publicidade confere ao produto e/ou serviço anunciado um lugar mágico, onde "vendem-se 'estilos de vida', 'sensações', 'emoções', 'visões de mundo', 'relações humanas', 'sistemas de classificação', 'hierarquia' em quantidades significativamente maiores que geladeiras, roupas ou cigarros”.

vii Depoimento de Inês, por mim coletado, em 2005, para subsidiar pesquisa sobre deslocamentos na atividade profissional, que será posteriormente tratada no presente artigo. 


\section{Quando a lógica da mudança de carreira e do consumidor se encontram}

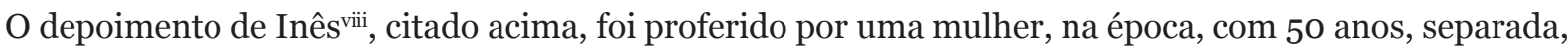
com um filho. Formada em engenharia, trabalhou na área até sua curiosidade levá-la para o mestrado em Administração. A partir dessa experiência, resolveu que não seria mais feliz como engenheira: precisava "mudar para ser feliz". Em nome da felicidade, Inês leu mapas astrais enquanto cursava o mestrado, e em meio à escrita da dissertação, trocou-o por uma nova graduação em psicologia. Terminou o curso, fez posteriormente uma pós-graduação, tornou-se professora e clinicou por alguns anos. Na ocasião da entrevista, já estava em novo processo de mudança profissional, segundo ela, mais sintonizado com o 'eu interior', com a necessidade de bem-estar. Como a definição de bem-estar se alterava ao longo dos anos, a profissão deveria acompanhar a mudança. Mas, mesmo que sua percepção do que a fazia feliz se alterasse, a busca pela essência da felicidade permanecia, constituindo-se em obrigação.

A fala de Inês é ilustrativa na discussão sobre a importância do trabalho como uma atividade criadora e que dá sentido ao 'eu interior'. Esta seria a chave para o que denominavam felicidade na profissão: sentimento de realização pessoal, de prazer no que se faz, não apenas visando a ganhos financeiros ou a prestígio. A crítica ao trabalho como obrigação e a valorização dessa categoria como caminho para a felicidade também encontram ressonância na publicidade. O banco Itaú Personnalité, direcionado para uma elite econômica, realizou, em 2007, uma campanha publicitária em que se propagava como um banco perfeito para os clientes por incentivá-los a se reinventarem. Um dos comerciais era direcionado ao trabalho, com a mensagem: "o mundo se divide entre dois tipos de pessoas: as que gostam do que fazem e aquelas que passam o tempo todo pensando no que poderiam estar fazendo se não tivessem que trabalhar. Trabalho é apenas o que paga as suas contas? Ou o que faz tudo valer a pena?”. ix

E o locutor, após tal narração, fechava o anúncio com o slogan "Itaú Personnalité: perfeito para você". A pergunta que se coloca é: quais motivos levam um banco de elite a se posicionar, em sua propaganda, como favorável à busca da felicidade através do trabalho? O discurso da propaganda não apoia o trabalho como um valor, fortalecimento do caráter ou simplesmente como um meio de ganhar dinheiro. O que o discurso sugere é uma valorização das pessoas ousadas, que não temem o risco de fazer o que gostam em busca da felicidade, mesmo que isso não pague imediatamente suas contas. Aliás, diga-se de passagem, é uma contradição em relação ao produto anunciado, que remunera o capital. Mas, então, por que o banco se dizia simpatizante daqueles que buscavam um trabalho "que faz tudo valer a pena", e não com os que desejavam apenas ter dinheiro suficiente para abrirem uma conta em um banco premium? Minha interpretação é de que o banco desejava se 'vender' como próximo a pessoas como Inês, e também como os outros entrevistados, que não tinham medo de buscar a própria felicidade. Desejava se posicionar como um banco ousado, parceiro e que, como outras categorias de produto e serviços, anunciava a felicidade como imperativa.

Como sublinha Freire Filho ${ }^{15}$, o discurso da felicidade perpassa, cada vez mais, as representações midiáticas nos jornais e nas revistas ${ }^{16}$. As persuasivas mensagens publicitárias ajudam a vender de calçados ortopédicos a sabão em pó ${ }^{17}$. E o mercado de autoajuda vira um indicador econômico, que mede a prosperidade de uma nação e, consequentemente, ganha voz na propaganda política dos governantes. A felicidade torna-se, então, não mais um estado de espírito ideal, mas um capital importante, um projeto individual, que todo sujeito tem como obrigação não apenas buscar, mas manter. Não é mais entendida como um "estado de exceção", "mas como uma livre determinação moral do indivíduo para engajar-se em sua reforma e crescimento pessoal" ${ }^{15}$. Desse modo, a propaganda do Itaú Personnalité assim como o jingle

viii Os nomes atribuídos aos informantes não são os verdadeiros. O recurso foi utilizado para proteger o anonimato dos entrevistados.

ix O comercial "Trabalho" que fazia parte da campanha "Perfeito para você" produzida pela DPZ foi veiculado em 2007 e pode ser assistido no link. https://www.youtube.com/watch?v=29a72_Jdijc. Acessado em 1/6/2016. 
feito para o comercial do supermercado Pão de Açúcar e para o produto carro-chefe da multinacional CocaCola encontram-se consonantes com os ecos de um imperativo cultural da felicidade.

É importante sublinhar que o assunto 'mudar de profissão visando ser feliz' é também recorrente nos periódicos especializados em carreira. A Box1824, especializada em tendências, divulgou um vídeo baseado em uma pesquisa internacional com os jovens millenials mostrando que, para essa geração, o sucesso no trabalho era igual a ter prazer, flexibilidade e possibilidade de criar e transformar. O vídeo finaliza com a seguinte indagação: "Você está fazendo o que gosta agora? Não? Então comece! [...]. Descubra o propósito da sua vida e faça acontecer. Amar o seu trabalho vai lhe colocar em movimento. É o único jeito de viver uma vida plena. Todos os dias”x. Para esses jovens millenials, a ideia de mudar o mundo é associada à mobilidade, ao imaginário empreendedor, à associação do trabalho com felicidade. Isto é, consideram fundamental trabalhar naquilo que gostam ${ }^{18}$.

Afinal, o que move pessoas, de várias idades oriundas de diversas profissões a se aventurarem por caminhos distintos dos construídos até então? As respostas dos informantes, independentemente da idade ou da ocupação ressaltaram aspectos emocionais em detrimento de questões práticas e racionais. Buscavam o prazer, o bem-estar e a felicidade. E, para alcançar tais metas, a ocupação cotidiana precisaria ser transformada em algo muito maior do que um 'mero' trabalho, do que um 'ganha-pão': deveria expressar os entrevistados. Conforme Colin Campbell ${ }^{19}$, o consumo se conecta a alguns dos elementos mais centrais do Ocidente contemporâneo, a partir das experiências e das sensações propiciadas pelo ato de consumir. Tal experimentação conduz ao autoconhecimento a partir do momento em que, ao consumirmos, monitoramos nossas reações, identificando nossas preferências, e nos definimos. A prerrogativa é a de um sujeito que escolhe produtos, serviços e estilos de vida, visando ao bem-estar e ao prazer no "supermercado individual" ${ }^{4}$. Tal modo de pensar é estendido a outras esferas da vida, como as relações pessoais e o trabalho, em que, segundo um entrevistado, "a única obrigação nossa nesta vida passa a ser buscar a felicidade". Mas o que está por detrás do discurso de 'mudar' para ser feliz?

a) a ideia de que é preciso ser feliz. A busca da felicidade aparece aí tanto como um direito quanto um dever: o dever de felicidade;

b) a ideia de que o trabalho não é mais uma narrativa de longo prazo que forja o caráter, como era até a Segunda Guerra Mundial $^{20}$, mas entendido como uma atividade flexível, que pode (e deve) ser alterada para melhor aderir aos projetos individuais;

c) a concepção de que não existe uma clivagem entre trabalho e lazer (um espaço privilegiado do tempo livre);

d) a ideia de uma gestão competente de si, de que o sujeito é um administrador de sua vida, que deve ser eficiente, um empreendedor de si.

\section{A busca da felicidade' e os caminhos percorridos}

Um dos entrevistados deu a seguinte declaração:

"[...] se você não está feliz com o que vocêfaz, você não consegue colocar a sua marca em nada, porque antes de tudo você precisa estar confortável".

"Colocar a marca" em todas as esferas da vida é considerado fundamental pelos entrevistados. O que se deve buscar? O protagonismo necessário para ser feliz. Mas que marca será essa? Antes de tudo, é importante localizar o "projeto de mudança" (categoria utilizada pelos próprios entrevistados) profissional

x All work and all play. Maciel L, Liedke L, Rodrigues R, roteiristas e diretores. Belo Horizonte: Bebop Studio; [2012?] [citado em 1 ago. 2014]. Disponível em: http://vimeo.com/44130258 
dentro de uma perspectiva mais ampla, a do indivíduo como um valor ${ }^{21}$. A valorização desse 'eu' único, indivisível, moral, livre e igual aos demais não é inata, mas moldada a partir da matriz epistemológica de uma determinada época e de um tipo específico de sociedade, categorizada como cultura ocidental moderna. Daí não se poder naturalizar tal conceito como se ele sempre tivesse existido e, de acordo com ele, as pessoas se comportassem do mesmo jeito em todos os lugares. Assim, a importância das escolhas nas vidas humanas, a ideia de trajetória, o pressuposto da racionalidade e o sentido do trabalho não são intrínsecos à condição humana, mas construídos segundo uma lógica na qual o sujeito é o ponto central. Nesse contexto, a profissão passa a ser uma expressão dessa individualidade, assim como as opções de lazer, o modo de se vestir e as preferências musicais definem o consumidor. Tal indivíduo, cujo papel se confunde com o de consumidor, é, portanto, livre para ser o que quiser e pensar os seus projetos, naturalmente dentro do "campo de possibilidades" 2 . Os projetos de felicidade, que inspiram as escolhas profissionais desses sujeitos, são também frutos da concepção de "sujeitos-agentes [em] processo permanente de interação sociocultural" ${ }^{23}$. E o pressuposto de que "nascemos para sermos felizes" se encontra enraizado na visão eudemonista do mundo, isto é, "voltada para satisfação dos ideais nesta vida - e não em outras" 24 . Assim como a preeminência das escolhas, o dever de felicidade é uma concepção ideológica, emergente na segunda metade do século XX, apoiada na ênfase que a cultura ocidental moderna ${ }^{\mathrm{xi}}$ confere aos projetos hedonistas.

Pascal Bruckner ${ }^{25}$ sublinha que a infelicidade não é mais apenas a ausência de felicidade, mas o fracasso desta. O indivíduo está condenado a ser feliz. Assim, cada um é responsável pela busca de sua própria felicidade e também por sua infelicidade. E, para ser feliz, é preciso ser competente, saber administrar suas escolhas visando ao bem-estar. A noção contemporânea de felicidade está relacionada ao que Colin Campbell denominou "hedonismo moderno", um hedonismo ancorado na emoção e no desejo, orientado para a busca do prazer, e não voltado para a "satisfação das carências", como era no passado, e que ele chamou de "hedonismo tradicional".

Na conduta hedonista moderna, a busca pelo prazer é motivada pelo desejo, sendo subjetivamente elaborada e mentalmente imaginada, além de exigir um julgamento de quem o experimenta. Afinal, nas palavras de Campbell ${ }^{26}$, em A ética romântica e o espírito do consumismo moderno, "procurar por prazer é expor-se a certos estímulos, na esperança de que estes detonarão uma resposta desejada dentro de si mesmo". A diferença entre o "hedonismo tradicional" e o "hedonismo moderno" indica as transformações históricas e culturais de que o sujeito ocidental participou. Na modernidade, os prazeres são internamente motivados e subjetivamente reconhecidos; "crenças, ações, preferências estéticas e respostas emocionais já não [são] automaticamente ditadas pelas circunstâncias, mas 'determinadas' pelos indivíduos”.

Para os entrevistados, ser feliz é um valor, uma obrigação para consigo mesmo. E a atividade profissional funciona como um meio de conquistar tal felicidade. O ideal é abraçarem uma atividade em que se sintam "decepcionados porque chegou a hora de ir embora, ao invés de ficarem o tempo todo olhando e contando quanto tempo falta para poderem ir embora”. E, quando percebem que não encaram seu trabalho assim, ao menos na maior parte do tempo, começam a se sentir infelizes. Entendem a frustração no dia a dia do trabalho como sinal de que algo não está bem e de que é preciso se reinventar, procurando novos horizontes. Mas tal reinvenção pressupõe várias fases: a identificação dessa insatisfação a partir do autoconhecimento, a busca de opções que tenham mais a ver com os projetos atuais e o investimento em um novo ofício. Se, conforme Bruckner ${ }^{25}$, a felicidade é uma promessa, vivenciada subjetivamente, para alcançá-la é preciso um condicionamento positivo. Tal busca é ativa, encarada como um dever, e embute uma noção de construção e de progresso. E, para melhorar a performance, podem-se combinar as várias práticas e terapias em princípio

xi Neste trabalho serão tomadas como partícipes da "cultura ocidental moderna" as sociedades que partilham de uma visão de mundo semelhante (pelo menos de forma mais geral) e que se veem como herdeiras da cultura europeia, tendo sido influenciadas pelas transformações ocorridas entre os séculos XVI e XVIII e fundamentando-se nos credos da racionalidade, da individualidade e de liberdade. 
com ideologias conflitantes entre si - como a junção da psicanálise com florais de Bach e Astrologia desde que juntas elas produzam um sentido global à 'bricolagem' do sujeito, uma lógica semelhante à do "consumidor moderno", na qual as subjetividades são integradas em modelos idealizados de acordo com os quais "podemos escolher como uma caixa de chocolates, apanhando os melhores, rejeitando outros".

Tais modelos idealizados de felicidade, que necessitam de uma busca ativa e de mudança por parte dos sujeitos, constituem as chaves de programas de televisão do tipo reality shows. Esses programas são voltados para autotransformações na vida pessoal, nos quais se mudam as formas de vestir, intervencionam-se faces para parecerem mais jovens e mais atraentes, transforma-se a residência para adquirir estilo e mudam hábitos alimentares em busca de um corpo delgado e mais saudável. Conforme analisou Everardo Rocha ${ }^{27}$, esses programas televisivos são "projetos de remodelação e reprogramação dos corpos e da vida", que funcionam como "uma verdadeira pedagogia e tecnologia de como ser aceito", pois é "preciso mudar para que nos aceitemos como somos" e para que se possa alcançar a felicidade desejada ao estar em consonância com o modelo estético vigente, no qual a própria subjetividade vira, sobretudo, uma sofisticada experiência de consumo.

\section{O trabalho não é exterior ao self}

O trabalho opera como uma marca, uma 'segunda pele' que deve se ajustar à trajetória e ao estilo do sujeito. Daí a necessidade de buscar uma nova representação profissional para si quando essa segunda pele já está desgastada, não aderindo mais às formas do corpo, devido às suas transformações internas e externas. Outro ponto é que as mudanças e segundas escolhas só fazem sentido a partir das concepções de experiência e de melhoramento. Luiz Fernando Duarte28 apresenta um novo modelo: o "dispositivo de sensibilidade", construído no Ocidente nos séculos XVII e XVIII analogamente ao "dispositivo de sexualidade", cunhado por Foucault. Nesse modelo, articulam-se três aspectos: a perfectibilidade, a experiência e o fisicalismo. Dois deles podem ser utilizados para se pensarem as narrativas dos informantes e presentes nos discursos sobre o consumo. A perfectibilidade tem a ver com a ideia de progresso, com o melhoramento buscado continuamente pelos sujeitos através da razão. Tal imagem é encontrada nos diversos discursos, visto que o processo de mudança é entendido como fruto do autoconhecimento, envolvendo o cuidado e o cultivo de si, bem como o uso de "objetos" (terapias, cursos, exercícios, medicamentos etc.) que supõem a melhoria qualitativa da interioridade desses sujeitos. Mas a razão, como sublinha Duarte, só pode se manifestar quando mediada pela experiência, na vivência subjetiva e na relação com o mundo exterior através dos sentidos. A experiência é muito enfatizada nas narrativas, assim como a necessidade de encontrar uma atividade que seja realizada com tanto prazer que se configure como um prolongamento do lazer. Assim, a busca pelo prazer e pela excitação na atividade profissional é tão importante quanto a procura pela "excitação no lazer", discutida por Elias e Dunning29. O ponto ótimo de excitação no trabalho também envolve uma estratégia de balanceamento entre o controle das emoções e a possibilidade de vivências múltiplas, para que a ocupação não se torne enfadonha pela rotina, nem excessivamente estressante pela saturação de estímulos.

\section{Considerações finais}

Alinhavar as múltiplas experiências de vida na direção de uma atividade laboral que dê prazer e os torne feliz, sem perder o controle de si, e sentindo-se um autor, que geriu os recursos encontrados em prol de uma autotransformação mais autêntica e plena, que leve ao reconhecimento interno da sensação de felicidade, é o discurso recorrente tanto dos que buscam os deslocamentos profissionais, como das narrativas disseminadas em programas televisivos e na propaganda. Afinal, os sujeitos têm 'obrigação de serem felizes' e se seus 'eus' são definidos pelo desejo e suas identidades informadas por seus gostos e preferências, por 
partilharem de certa "visão de mundo" característica da "cultura do consumo". Afinal, "o consumidor [...] é um exemplo ou aspecto do indivíduo privado empreendedor que está no centro da própria noção de modernidade" ${ }^{\circ}$. Por conseguinte, o consumo não pode ser visto apenas como uma transação comercial e econômica, mas deve ser enxergado de forma mais complexa, como centro da própria modernidade, por ser "um meio crucial de exercermos nossa cidadania no mundo social" $25 \mathrm{e}$ uma das formas mais importantes de reprodução da vida cotidiana e construção de subjetividade. Assim, ao pensarmos as metamorfoses profissionais como as narrativas publicitárias e de ficção televisiva, estamos falando de indivíduos que acreditam que através de seus desjos e escolhas constroem para si uma identidade, a partir da qual o trabalho é parte fundamental dessa expressão de si e a felicidade prerrogativa, pois "nasceram para ser felizes".

\section{Referências}

1. Siciliano TO. Reinventando a si mesmo no fio da carreira: uma reflexão sobre as metamorfoses nas segundas escolhas profissionais [dissertação]. Rio de Janeiro: Fundação Getúlio Vargas; 2006.

2. Bourdieu P. Coisas ditas. São Paulo: Brasilense; 1990.

3. Felicidade. In: Ferreira ABH. Novo dicionário Aurélio da Língua Portuguesa. 4 ed. Ferreira MB, Anjos M, coordenadores. Curitiba: Positiva. p. 885.

4. Morin E. Cultura de massas no século XX: o espírito do tempo. Rio de Janeiro: Forense Universitária; 2011. (Neurose, v. 1).

5. Kellner D. A cultura da mídia: estudos culturais: identidade e política entre o moderno e o pós-moderno. Bauru, SP: EDUSC; 2011.

6. Rocha E, Pereira C, Aucar B. Os anúncios nas revistas ilustradas: imaginário e valores brasileiros no início do século XX. In: __ _ organizadores. Cultura e imaginação publicitária. Rio de Janeiro; PUC: Mauad; 2013. P. 21-68.

7. Rocha E. Magia e capitalismo: um estudo antropológico da publicidade. São Paulo: Brasiliense; 1995.

8. Carrazcosa JA. Razão e sensibilidade no texto publicitário. São Paulo: Futura; 2004.

9. Maffesoli M. O imaginário é uma realidade. FMC, 2001 ago;1(15):74-82.

10. Machado A. A televisão levada a sério. São Paulo: SENAC; 2000.

11. Pallotini R. Dramaturgia de televisão. São Paulo: Perspectiva; 2012.

12. Castro G. Notas sobre a inserção da telenovela brasileira na cibercultura. Comunicación, 2012;1(10):32-41.

13. Velho G. Projeto e metamorfose: antropologia das sociedades complexas. Rio de Janeiro: Jorge Zahar Editor; 2003.

14. Campbell C. Eu compro, logo, sei que eu existo: as bases metafísicas do consumo moderno. In: Barbosa L, Campbell C, organizadores. Cultura, consumo e identidade. Rio de Janeiro: FGV, 2006. p. 47-64.

15. Castro G. A felicidade na era de sua reprodutibilidade científica: construindo pessoas cronicamente felizes. In: Freire-Filho J, organizador. Ser feliz hoje: reflexões sobre o imperativo de felicidade. Rio de Janeiro: FGV; 2010. p. 49-82. Por favor, confirmar o autor do capítulo, pois na referência está Castro e no texto Freire Filho. Eliminamos a referência '19' da versão anterior, pois ela se repete nesta referência.

16. Carvalho C. O consumo e a representação da felicidade em 40 anos de propaganda brasileira [dissertação]. Goiânia: Universidade Federal de Goiânia; 2010.

17. Freire-Filho J. Fazendo pessoas felizes: o poder moral dos relatos midiáticos. Anais do XIX Encontro da Compós; 2010 jun 8-11; Rio de Janeiro: PUC-Rio; 2010.

18. Casaqui V. A juventude e o sonho brasileiro: espírito do capitalismo, empreendedorismo social, trabalho e consumo nas pesquisas de tendências. Anais do IV Congresso Internacional em Comunicação e Consumo, IV Encontro de GTS em Comunicação e Consumo, IV Simpósio Internacional, I Encontro Binacional, I Ciclo de Aulas abertas e Oficinas; 2014 out 8-10; São Paulo: ESPM; 2014.

19. Campbell C. A ética romântica e o espírito do consumismo moderno. Rio de Janeiro: Record, 2001. 
20. Sennett R. A corrosão do caráter: consequências pessoais do trabalho no novo capitalismo. Rio de Janeiro: Record; 2004.

21. Dumont L. O individualismo: uma perspectiva antropológica da ideologia moderna. Rio de Janeiro: Rocco; 2000.

22. Velho G. Projeto e metamorfose: antropologia das sociedades complexas. Rio de Janeiro: Jorge Zahar; 2003.

23. Velho G. Cultura subjetiva e projetos de felicidade. In: , organizador. Ser feliz hoje: reflexões sobre o imperativo de felicidade. Rio de Janeiro: FGV; 2010. p. 227-238.

24. Duarte LFD. Muitas felicidades! Diferentes regimes do bem nas experiências de vida. In: organizador. Ser feliz hoje: reflexões sobre o imperativo de felicidade. Rio de Janeiro: FGV; 2010.' p. 239-256.

25. Bruckner, P. A Euforia perpétua: ensaio sobre o dever de felicidade. Rio de Janeiro: Difel, 2002.

26. Campbell, C. A ética romântica e o espírito do consumismo moderno. Rio de Janeiro: Record, 2001. p.90-110.

27. Rocha E. Coisas estranhas, coisas banais: notas para uma reflexão sobre o consumo. In: Rocha E, Almeida MIM, Eugenio F. Comunicação, consumo e espaço urbano: novas sensibilidades nas culturas jovens. Rio de Janeiro: PUC-Rio: Mauad; 2006. p.15-34.

28. Duarte LFD. O império dos sentidos: sensibilidade, sensualidade e sexualidade na cultura ocidental moderna. In: Heilborn ML, organizadora. Sexualidade: o olhar das ciências sociais. Rio de Janeiro: Jorge Zahar; 1999. p. 21-30.

29. Elias N; Dunning E. A busca da excitação. Lisboa: Difel; 1992.

30. Slater, D. Cultura do consumo e modernidade. São Paulo: Nobel, 2002. p.13-33. 